\title{
Black esophagus: Necrosis aguda esofágica en paciente con shock hemorrágico
}

\author{
Enrique Chicote-Álvarez ${ }^{1 *}$, María J. Domínguez-Artiga1 , Marta González-Martínez² y \\ Álvaro Terán-Lantarón ${ }^{2}$ \\ ${ }^{1}$ Servicio de Medicina Intensiva; ${ }^{2}$ Servicio de Aparato Digestivo. Hospital Universitario Marqués de Valdecilla, Santander, Cantabria, España
}

\section{Resumen}

La necrosis aguda esofágica (black esophagus) es una condición infrecuente asociada con hipoperfusión tisular. La etiología es multifactorial. El tratamiento consiste fundamentalmente en tratar la situación desencadenante. Puede presentar complicaciones como perforación o estenosis esofágica. Generalmente es reversible al mejorar la patología desencadenante.

Palabras clave: Black esophagus. Shock. Sangrado digestivo.

\section{Black esophagus: Acute esophageal necrosis associated with haemorrhagic shock}

\section{Abstract}

Acute esophageal necrosis (black esophagus) is an infrequent condition associated with tissue hypoperfusion. The etiology is multifactorial. The treatment consists of treating the triggering situation and keeping the patient nil-per-os. It can present complications such as perforation or esophageal stenosis. It is usually reversible by improving the triggering pathology.

Key words: Black esophagus. Shock. Gastrointestinal bleeding.

\section{Correspondencia:}

Enrique Chicote-Álvarez

E-mail: chicotelogro@ hotmail.com
Fecha de recepción: 07-05-2018

Fecha de aceptación: 20-10-2018

DOI: 10.24875/RAA. 18000012
Disponible en internet: 05-02-2019 Rev Argent Anestesiol. 2018;76(2):104-105 www.revistaargentinaanestesiologia.com 0370-7792 @ 2018 Federación Argentina de Asociaciones, Anestesia, Analgesia y Reanimación. Publicado por Permanyer México SA de CV. Este es un artículo Open Access bajo la licencia CC BY-NC-ND (http://creativecommons.org/licenses/by-nc-nd/4.0/) 


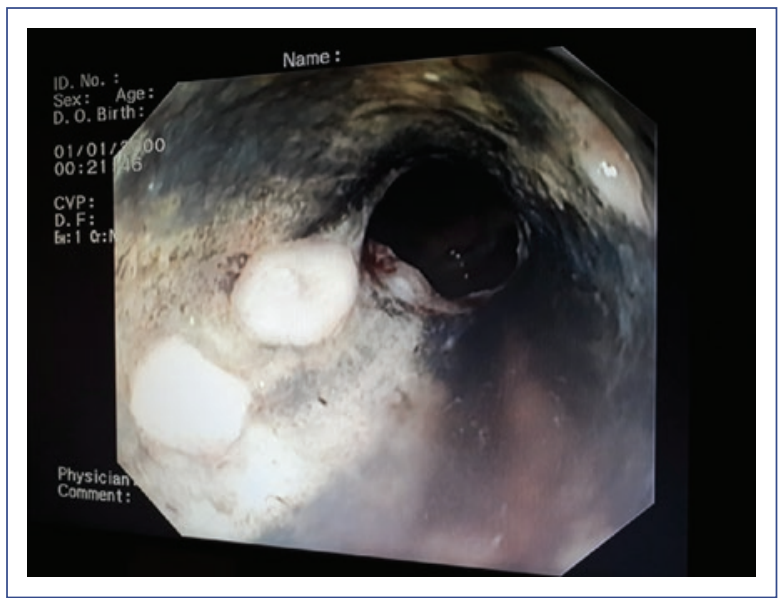

Figura 1. Endoscopia digestiva alta: Mucosa esofágica de aspecto negruzco (black esophagus), compatible con una situación de necrosis aguda esofágica debida a shock hipovolémico.

Mujer de 61 años, con antecedentes de enolismo grave, que acudió a Urgencias por un cuadro de deterioro general en los últimos 15 días, hasta imposibilitarle la bipedestación. Se objetivaron datos de shock, hemoglobina de $4 \mathrm{~g} / \mathrm{dl}$ y lactato de $86.0 \mathrm{mg} / \mathrm{dl}$ en la analítica y la salida de contenido hemático por la sonda nasogástrica. Ante sospecha de shock hemorrágico por hemorragia digestiva alta, se procedió a intubación orotraqueal, resucitación con fluidos y hemoderivados y endoscopia urgente. Se objetivó ulcus gástrico Forrest llc y mucosa esofágica negruzca, compatible con situación clínica de baja perfusión (Fig. 1). El estudio se completó con una angiotomografía computarizada toracoabdominal que descartó sangrado activo a otro nivel. Tras la estabilización, la paciente presentó buena evolución, sin nuevos episodios de sangrado, y pudo ser extubada al tercer día del ingreso.

La necrosis aguda esofágica (black esophagus) es una condición infrecuente asociada con hipoperfusión tisular $^{1}$. Se relaciona, entre otras situaciones, con shock hipovolémico. La etiología es multifactorial, resultado de una combinación de hipoperfusión tisular, pérdida de la función de la barrera endoletial y reflujo de contenido gástrico. El tratamiento consiste fundamentalmente en tratar la situación desencadenante, mantener dieta absoluta e infusión endovenosa de fármacos inhibidores de la bomba de protones ${ }^{2}$. Puede presentar complicaciones como perforación o estenosis esofágica. Generalmente es reversible al mejorar la patología desencadenante.

\section{Bibliografía}

1. Gurvits GE. Black esophagus: Acute esophageal necrosis síndrome. World J Gastroenterol. 2010; 16(26): 3219-25.

2. Shafa S, Sharma N, Keshishian J, Dellon ES. The Black Esophagus: A Rare But Deadly Disease. ACG Case Rep J. 2016;3(2):88-91. 